\title{
COMPARING TWO DIFFERENT ANGULATED ABUTMENT DESIGNS ON MARGINAL BONE LOSS AROUND DIVERGENT TWO IMPLANTS RETAINING MANDIBULAR OVERDENTURES: A RADIOGRAPHIC PROSPECTIVE STUDY
}

\author{
Marwa Ahmed Mohamed*
}

\begin{abstract}
Objectives: the aim of this study was to radiographically compare the influence of two different angulated abutment designs on marginal bone loss around 30-degree divergent two implants retaining mandibular overdentures.

Materials and Methods: Thirty six patients were selected. For each patient, two distally inclined dental implants $(3.5 \mathrm{~mm} \times 13 \mathrm{~mm})$ were bilaterally inserted in the canine regions by using stereolithography stent. Patients were divided into two groups as follows: Group AB $(n=18)$ : Patients received two ball attachments which were screwed to the angulated overdenture abutments. Group AL $(n=18)$ : Patients received two locator attachments which were screwed to the angled overdenture abutments. Marginal bone loss was assessed at the time of implant insertion (baseline), and after every 12 months up to 36 months by using digital periapical radiographs.
\end{abstract}

Results: Both groups showed insignificant difference at the mesial aspect in peri- implant bone loss at 12 months. But, ball group recorded a significant increase in peri-implant bone loss $(0.26)$ ) in comparison to locator group (0.23). But, at the distal aspect there was a statistically insignificant difference between both groups at 12,24 and 36 months

Conclusion: The locator attachment can be considered more favorable than the ball attachments regarding the peri-implant bone loss around 15 distally inclined implants used for assisting mandibular complete over denture.

KEY WORDS: Mandibular implant overdenture, Angled abutment and peri-implant bone loss.

\section{INTRODUCTION}

Implant supported overdentures have been proven by many studies to have $94 \%$ to $100 \%$ success rates $^{1}$. This effective treatment option of- fers a solution for both psychosocial and functional problems associated with maladaptive conventional denture wearers ${ }^{2,3}$. Placing two implants in the canine region of edentulous mandible is considered

\footnotetext{
* Lecturer of Prosthodontics, Faculty of Dentistry, Mansoura University, Egypt.
} 
an affordable and reasonable alternative to implant fixed complete dentures ${ }^{2,4,5}$. These implants can be splinted with a bar designs or connected individually to the denture with stud attachments such as ball or locators ${ }^{5,6}$.

It has been recommended that implants should be placed parallel to one another and in the path of the prosthesis insertion, as well as perpendicular to the occlusal plane ${ }^{2,7}$. However, the procedure is limited by the bone quality, anatomical structure and clinical experience ${ }^{8,9}$. Lack, inaccurate, or instability of the surgical guide during surgery can result in implant inclination especially in the mandible ${ }^{\mathbf{1 0 , 4}}$.

It was reported that less experienced surgeons may place implants having greater facial or lingual inclination. ${ }^{11,3}$. Consequently, bilateral placement of implants in the canine position within a curved edentulous arch may diverge them from each other in the frontal plane ${ }^{12}$. Clinically, this condition of distal implant inclination may be noticeable when there is a facial concavity. Computer-guided implant placement may eliminate the need for bone grafting, and even raising a flap, however, this approach remains inaccessible for elder patients with poor socio-economic conditions and who of limited financial resources ${ }^{13,8}$. Lack of implant parallelism can challenge a dentist when selecting the proper overdenture attachment system ${ }^{14}$. An ideal attachment system should provide a high and stable retentive force with a low lateral force to the implant, particularly if the implants are inclined ${ }^{5,9}$.

Although the standard ball attachment is considered to be the most widely used of all the systems available, it only allowed angulation variations up to $20^{\circ}$ (up to $10^{\circ}$ convergence each) ${ }^{3,1}$. Surgical re-treatment or alternative prosthetic methods were suggested to compensate for malpositioned implants in the early planning stage of treatment ${ }^{3,4}$. Some of prosthetic designs for correction of inclined implants included splinting with bar or use of Locator attachment in replace of ball patrices.
The bar design will result in additional cost, possibility of gingival hyperplasia, encroachment on the tongue space with tapered arches ${ }^{1,2}$. Although the classic Locator attachment can accomodate up to 40 degree of divergence between implants, frequent wear and loss of retention has been reported as complications ${ }^{14,5,6,7}$.

Custom-made cast ball or cast-to Locator attachments were also used to ensure parallelism between the two attachments in a cost-effective manner ${ }^{2,3,15}$. Recently, pre-manufactured angled abutments were available in the implant market for correction of inclined implants retaining overdentures that may be less technique-sensitive, and easier to clean.The authors have directed their attention strategies for improving the prosthetic outcome with concern to predictable retention and avoiding premature wear of the retentive matrices $3,7,14,10$.

As the inclined implants are more prone to destructive forces, the marginal bone loss are more likely to occur around these implants ${ }^{3,12,16},{ }^{17}$. To the best of the authors' knowledge, the literature lacks clinical studies that compare the effect of angulated stud attachment systems on the success rate of inclined implants retaining mandibular overdentures. Therefore; the aim of this study was to radiographically compare the influence of two different angulated abutment designs on marginal bone loss around 30-degree divergent two implants retaining mandibular overdentures.

\section{MATERIALS AND METHODS}

\section{Study design}

This is an observational prospective study with a 3-year follow-up was conducted on thirty six participants aged 58 to 68 years (mean 63.4 years; 9 females and 27 male) having completely edentulous ridges. Participants were admitted to prosthodontics clinic for oral rehabilitation by using maxillary conventional denture opposing mandibular two-implant retained overdenture in 
Faculty of Dentistry, Mansoura University. The study was performed in the time period between 2015 and 2019. The study was conducted according to the Helsinki Declaration of 2008 and approved by Local Dental Research Ethical Committee. All the study participants were randomly selected and informed about the study procedures; the consent form was discussed and declared prior to their signatures. Based upon the results of Hegazy et $\mathrm{al}^{18}$, using alpha $(\alpha)$ level of $(5 \%)$ and Beta $(\beta)$ level of $(10 \%)$ i.e. power $=90 \%$; the study will include a minimum of 18 subjects per group for a total of 36 subjects. Sample size calculation was performed using IBM $®$ SPSS $®$ Sample Power ${ }^{\circledR}$ Release.

The inclusion criteria included completely edentulous participants who were reported as maladaptive to conventional mandibular denture. All patients were in good general health without disorders that would contraindicate implant treatment. Participants have been initially screened for sufficient inter-arch space and sufficient mandibular residual alveolar ridge that verified by digital panoramic x-ray (Soredex, Helsinki, Finland). CBCT revealed sufficient bone volume for placement of implants at least $3.5 \mathrm{~mm}$ wide and $13 \mathrm{~mm}$ long in the canine position bilaterally. Buccal bone concavities that allow 15 degrees tilted implant placement from the midline without additional augmentation procedures. Excluded participants were who reported with history of parafunctional habits, alcoholism, heavy smoking ( $>10$ cigarettes per day), TMD, neuromuscular disorders or metabolic disorders affecting bone such as diabetes.

\section{Pre-surgical procedures}

All participants received a new set of conventional complete dentures followed by performing CBCT scan for planning the implant placement $(13 \mathrm{~mm}$ length and $3.5 \mathrm{~mm}$ width were installed bilaterally at the canine region) based on computer guided flapless surgery.3D-imagingwas used to insure implant placement (Implant direct, USA) within the most volume of bone in the canine region with 15 degree of divergence from the median vertical axis of the mandible. (Fig. 1).

Patients with presence of bony perforations or thin $(<1 \mathrm{~mm})$ facial or lingual cortical plates of bone around the planned implant were excluded. A stereolithographic (STL) surgical guide was fabricated by dual-scan technique for flapless implant insertion. ${ }^{19}$.

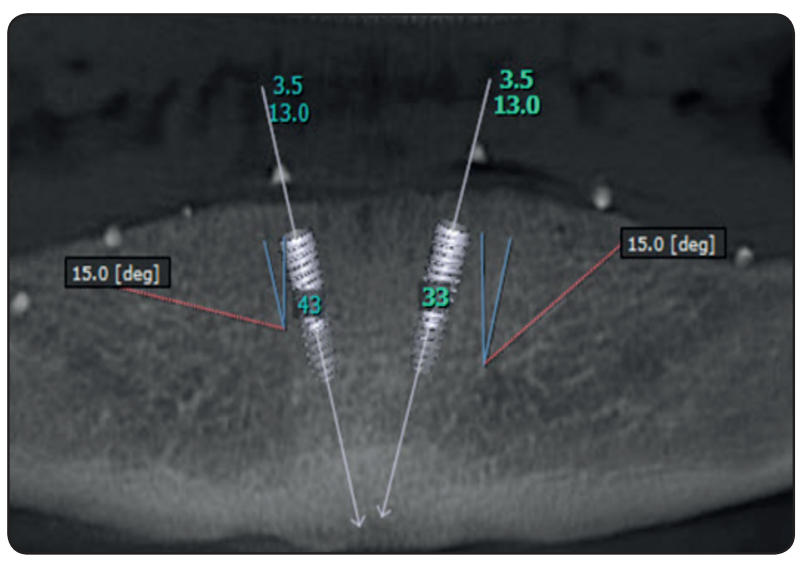

Fig. (1): The predetermined location, inclination and depth of canine implants in CBCT.

\section{Surgical procedures}

Surgical technique followed two surgical stages according to..$^{20}$ each participant received 2 implants by using STL guide with different sleeve inserts. Local anaesthetic solution was infiltrated and then the surgical guide was stabilized intraorally by using silicone bite registration in maximal intercuspation followed by fixation with surgical anchor pins. Tissue punch was used to cut through the soft tissues. The drilling protocol was consecutively done until reaching the final drill (Drill Guide, Implant Direct, Korea). The guide was removed at the moment of implant insertion. Osteotomy sites were irrigated by copious amounts of sterile normal saline as recommended by the manufacturer then the implants were inserted with the torque wrench until 
the final seat at $35 \mathrm{Ncm}$ to ensure implant initial stability (Fig.2) Cover screws were screwed over the implants and 3-0 sutures were done to stabilize the blood clot. The denture base corresponding to the implants was relieved and relined with tissue conditioner. Antibiotics, analgesics, and 0.12 chlorhexidine mouth rinse were administered according to standard protocol. Participants were informed for oral hygiene measures and the scheduled follow-up visits.

\section{Prosthodontic Procedures}

After 3-months osseointegration period, the cover screws were unscrewed and the healing abutments were screwed into the implants for 2 weeks, the denture base was adjusted and relined consequently with no rocking or interference. The heal-

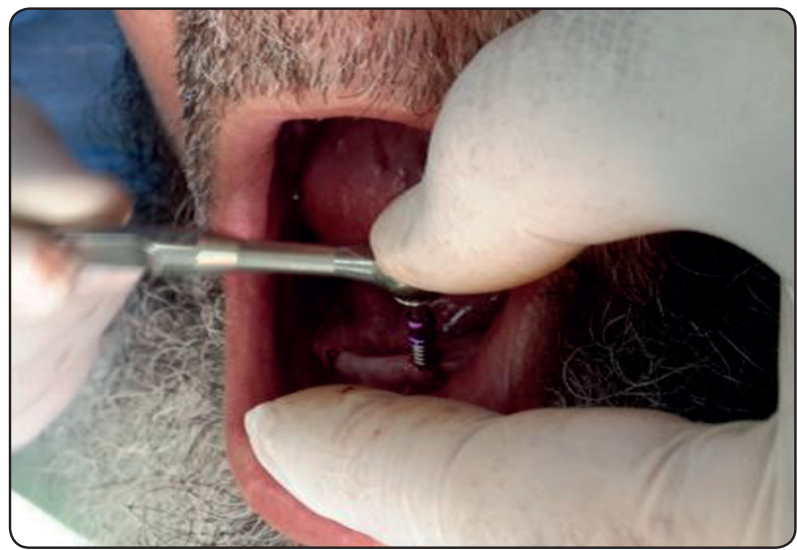

Fig. (2): The implant insertion into the prepared site using the torque wrench

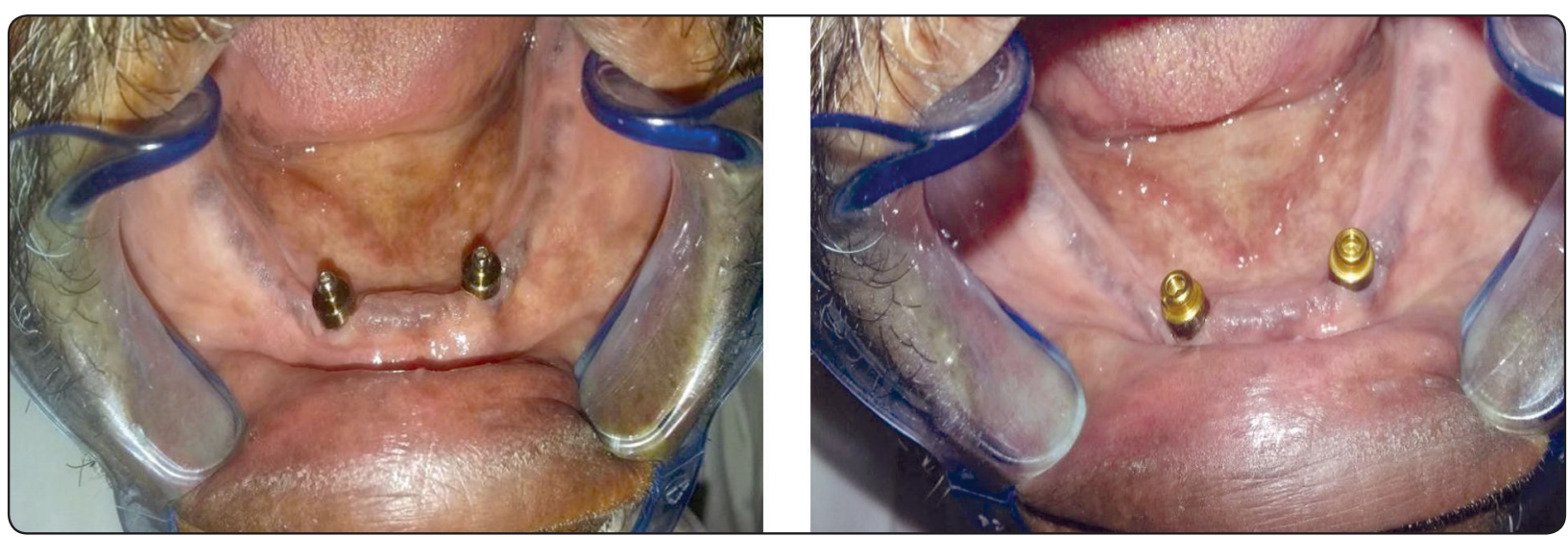

Fig. (4): (a) Ball attachments screwed into the angled abutments in group (AB); (b) locator attachments screwed into the angled abutments in group (AL) two-piece angled overdenture abutments torqued to 20 N/cm (Implant Direct, Korea).

Suitable heights of $15^{\circ}$ transmucosal piece were selected to correct implant inclination and to ensure parallelism of both stud attachments (Fig.3). According to the type of the retentive parts, patients were randomly divided with a sealed envelope technique into 2 equal groups; Group $\mathbf{A B}(n=18)$ where participants received two angulated abutment with ball retentive piece. Group AL: $(n=18)$ where participants received two angulated abutment with Locator retentive piece (Fig. 4 a, b). Block-out spacers were placed over the head of each abutment and then a processing cap/insert was inserted into each (Fig. 5 a,b). A recess was prepared in the mandibular denture to accommodate the corresponding

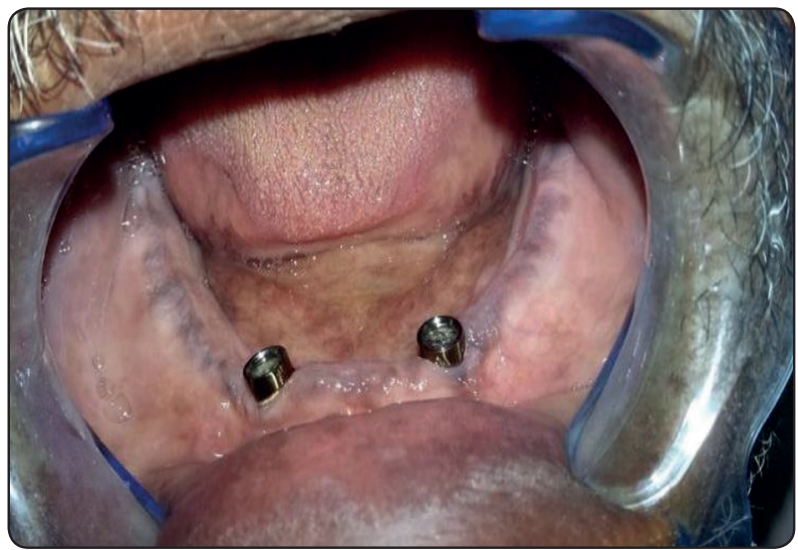

Fig. (3): Angled abutments (15 degree) were screwed into the implants. ing abutments were replaced with pre-manufactured 


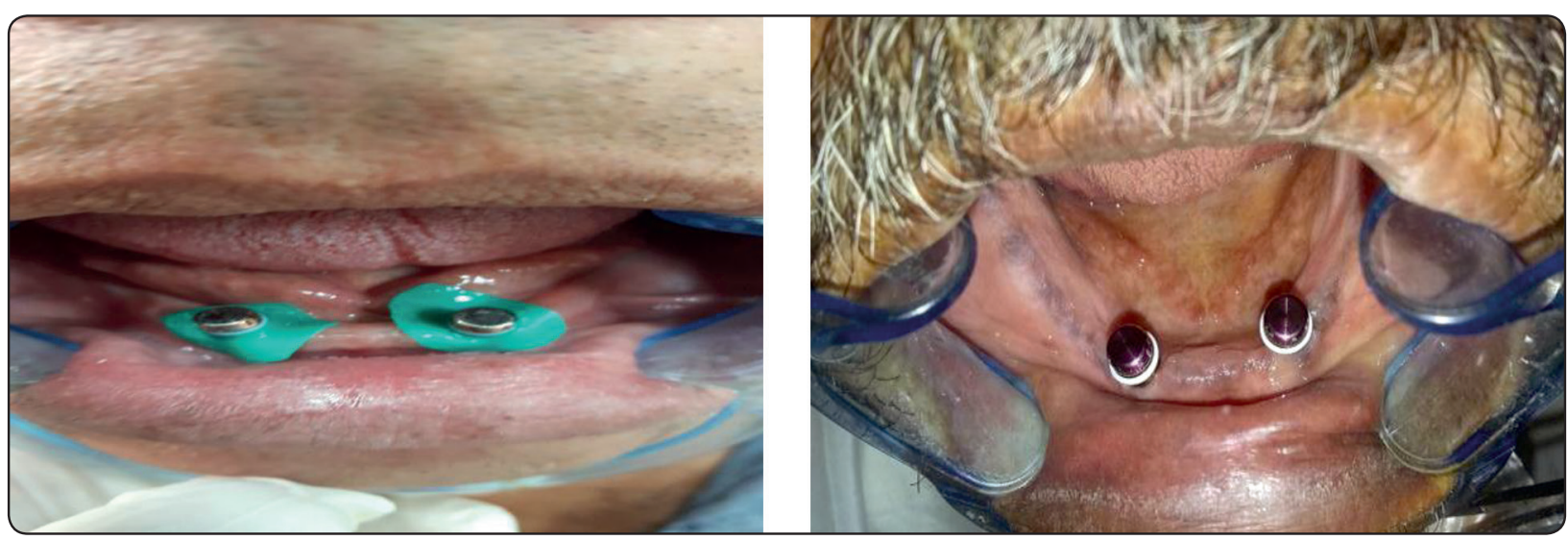

Fig. (5): (a) Female metal housings placed over their corresponding patrices in group (AB)); (b) Female metal housings placed over their corresponding patrices in group (AL).

abutment with no contact to the denture base ensuring space for the pick-up procedure by the autopolymerizing acrylic resin (Repair Material, Dentsply, York, Pa). The patient was instructed to bite into centric occlusion until the resin had polymerized. The denture was then removed, inspected, and excess resin was trimmed. Occlusion was adjusted and refined. The processing caps/ inserts were replaced with color-coded retention plastic inserts. Patients were enrolled in an oral hygiene program with a recall visit every 12 months; their compliance after each year was monitored. Radiographic records of all implants were taken at baseline that were immediately after loading the implants through the stud attachments.

\section{Radiographic Evaluations}

By utilization of a film-aiming device (Dentsply RINN, Rinn Cooperation, USA) assisted bycustom acrylic template a series of digital periapical radiographs were taken using and long-cone paralleling technique according to Abdel-khalek ${ }^{21}$. Observation intervals were scheduled immediately at overdenture insertion (baseline) and after every 12 months up to three years. Radiographic measurements were performed by one examiner to the nearest $0.01 \mathrm{~mm}$ using software (Corel Draw v12.iso, Corel Corporation, Ottawa, Canada) at 400x magnification. For estimating the peri-implant bone loss, implant shoulder was used as a reference point. The distances from the reference point to the most coronal implant-bone contact mesially and distally were measured. Marginal bone loss was calculated by subtracting the marginal bone level measured at each observational time from the previous measurement until reaching the baseline measurements $^{22}$ (Fig.6). Negative values represent bone loss while positive values represent bone gain. The calculated data of bone loss at each aspect were averaged for both right and left implants. The data were recorded and tabulated for statistical analysis.

\section{Statistical analysis}

Data were analyzed using the Statistical Package of Social Science (SPSS) program for Windows (Standard version 24). The normality of data was first tested with Shapiro test. Continuous variables

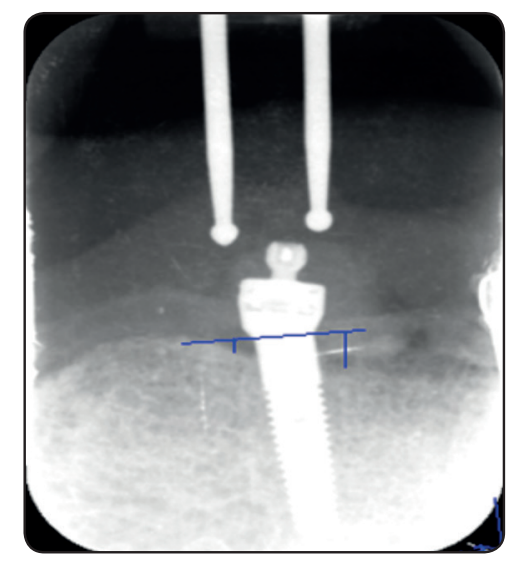

Fig. (6): Standart radiographic technique and measurements. 
were presented as median (min-max). The two groups were compared with Manny Whitney test while paired two groups were compared with Wilcoxon signed rank test. Spearman correlation was used to correlate continuous data For all above mentioned statistical tests done, the threshold of significance is fixed at 0.05 ). The results was considered significant when the probability ( $\mathrm{p}$ value $\leq 0.05$ ). The smaller the $p$-value obtained, the more significant are the results.

\section{RESULTS}

Table 1 and Fig. 7 showed comparison of periimplant bone loss at the mesial aspect between $\mathrm{AB}$ (Ball group) and AL (Locator group) at different follow up periods of the study. At 12 months, there was insignificant difference in peri-implant bone loss between the two groups. But, ball group recorded a significant increase in peri-implant bone loss $(0.26)$ in comparison to locator group (0.23). At 24 and 36 months, there was significant difference in bone loss between the two groups ( $\mathrm{p}<0.05)$. Although periimplant bone loss recorded a significant decrease in $\mathrm{AB}$ group at 12,24 and 36 months $(0.26,0.035$ and 0.04 , respectively) and in AL group (0.23, 0.04 and 0.04 , respectively).

As showen in Table (2) and Fig (2), on comparing peri-implant bone loss at the distal aspect between the two groups in this study, there was a statistically insignificant difference between both groups at 12 , 24 and 36 months. Peri-implant bone loss recorded a significant decrease in $\mathrm{AB}$ group at 12, 24 and 36 months $(0.31,0.09$ and 0.09 , respectively) and in AL group and (0.36, 0.07 and 0.09 , respectively). In the other hand, even peri- implant bone loss located in the normal range of accepted criteria but it was higher at the distal aspect than that at the mesial aspect for both groups.

Table 3,4 showed a statistically weak positive correlation between peri-implant bone loss in the mesial and in the distal aspects and time of measurments.

TABLE (1): Comparison between ball and locator bone loss(Mesial) at different follow up

\begin{tabular}{|l|c|c|c|c|}
\hline \multicolumn{1}{|c|}{ Mesial } & Ball group (n=18) & Locator group (n=18) & Mann whitney test & p-value \\
\hline Mesial 1(M1) & $0.26(0.05-0.55)$ & $0.23(0.09-0.37)$ & 0.792 & 0.428 \\
\hline Mesial 2(M2) & $0.035(0.0-0.11)$ & $0.04(0.01-0.4)$ & 0.560 & 0.576 \\
\hline Mesial 3(M3) & $0.04(0.0-0.08)$ & $0.04(0.0-0.08)$ & 0.0 & 1.0 \\
\hline Wilcoxon signed rank test & M1 P1 $\leq 0.001 *$ & P1 $\leq 0.001 *$ \\
& M2 P2 $\leq 0.001 * 0.001 *$ \\
& P3 P3 $=0.403$ & \\
& P3 $=0.649$ & & \\
\hline
\end{tabular}

Data were expressed as median (Min-Max)

P2: Comparison between Mesial 1 and Mesial 3

\section{P1: Comparison between Mesial 1 and Mesial 2}

P3: Comparison between Mesial 2 and Mesial 3

TABLE (2): Comparison between ball and locator bone loss (Distal) at different follow up

\begin{tabular}{|c|c|c|c|c|c|}
\hline Distal & Ball group $(n=18)$ & Locator group $(\mathrm{n}=18)$ & & Mann whitney test & $\mathrm{p}$-value \\
\hline Distal 1 & $0.31(0.02-0.58)$ & $0.36(0.21-0.52)$ & & 1.55 & 0.121 \\
\hline Distal 2 & $0.09(0.0-0.17)$ & $0.07(0.0-0.12)$ & & 1.37 & 0.172 \\
\hline Distal 3 & $0.09(0.01-0.21)$ & $0.09(0.01-0.15)$ & & 0.448 & 0.652 \\
\hline $\begin{array}{cc}\text { Wilcoxon } & \text { D1 } \\
\text { rank test } & \text { D3 }\end{array}$ & $\begin{array}{l}\mathrm{P} 1 \leq 0.001^{*} \\
\mathrm{P} 3=0.589\end{array}$ & $\mathrm{P} 1 \leq 0.001$ & D2 & $\mathrm{P} 2 \leq 0.001^{*}$ & $\mathrm{P} 2 \leq 0.001 *$ \\
\hline
\end{tabular}

Data were expressed as median (Min-Max) P2: Comparison between Mesial 1 and Mesial 3
P1: Comparison between Mesial 1 and Mesial 2 P3: Comparison between Mesial 2 and Mesial 3 


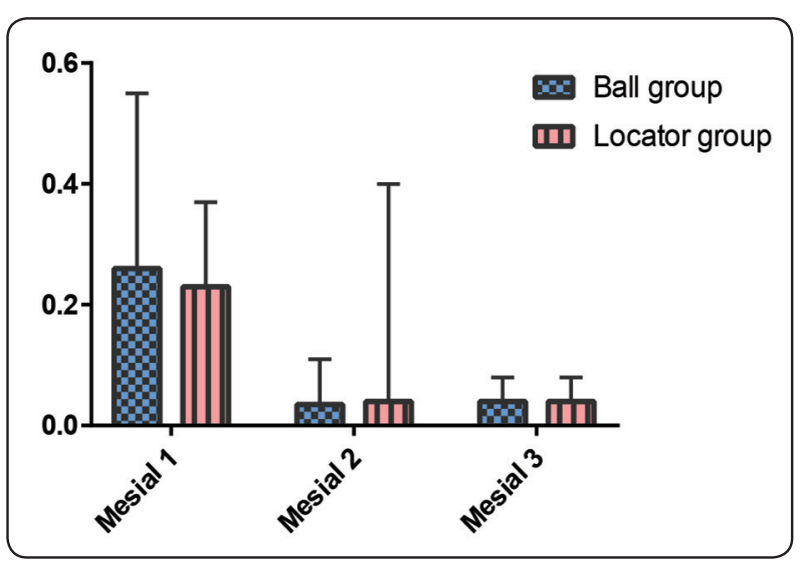

Ball and locator bone loss (Mesial) at different follow up

TABLE (3): Correlation between mesial and distalbone loss in Ball group

\begin{tabular}{|l|c|c|c|c|c|c|}
\hline \multirow{2}{*}{} & \multicolumn{2}{|c|}{ Mesial 1 } & \multicolumn{2}{c|}{ Mesial 2 } & \multicolumn{2}{c|}{ Mesial 3 } \\
\cline { 2 - 7 } & $\mathrm{r}$ & $\mathrm{p}$ & $\mathrm{r}$ & $\mathrm{p}$ & $\mathrm{r}$ & $\mathrm{P}$ \\
\hline Distal 1 & 0.522 & $0.026^{*}$ & - & - & - & - \\
\hline Distal 2 & - & - & 0.132 & 0.601 & - & - \\
\hline Distal 3 & - & - & - & - & 0.534 & $0.022^{*}$ \\
\hline
\end{tabular}

Spearman correlation

\section{DISCUSSION}

The current study recorded $100 \%$ success rate during the evaluation period of both groups and located within the normal range of acceptable criteria for implant success .It may be due to many factors such as the presence of all patients from the beginning of the study until its end and their commitment with all the instructions and adequate taking care of their oral hygiene. The findings of this study were in concurrent with $\mathrm{Kim}$ et al, ${ }^{23}$ as the marginal bone level changes were less than 1.5 $\mathrm{mm}$ in the first year after implant insertion and the annual bone loss was less than $0.2 \mathrm{~mm}$.

Despite the retentive force required by the attachment system, it should exert low lateral force to the implant, particularly if these implants are inclined $^{5,9}$. Some of prosthetic designs were suggested

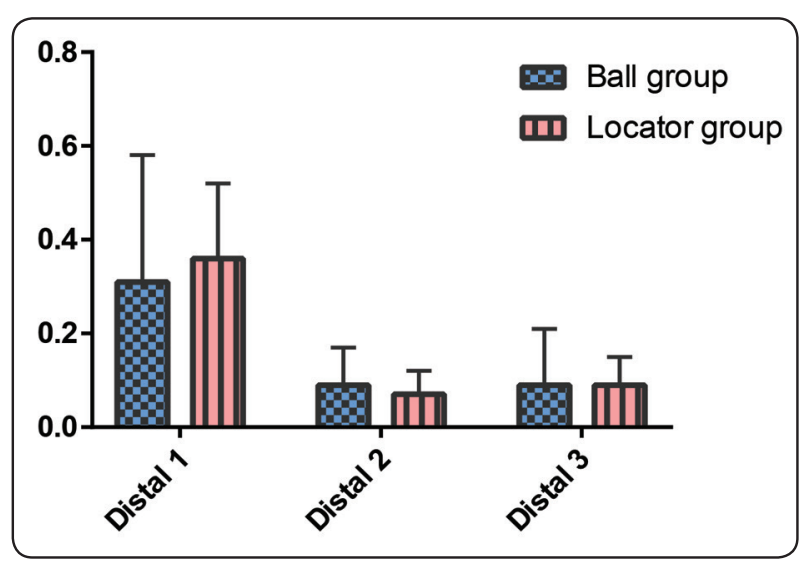

Ball and locator bone loss (Distal) at different follow up

TABLE (4): Correlation between mesial and distalbone loss in locator group

\begin{tabular}{|l|c|c|c|c|c|c|}
\hline \multirow{2}{*}{} & \multicolumn{2}{|c|}{ Mesial 1 } & \multicolumn{2}{c|}{ Mesial 2 } & \multicolumn{2}{c|}{ Mesial 3 } \\
\cline { 2 - 7 } & $\mathrm{r}$ & $\mathrm{p}$ & $\mathrm{r}$ & $\mathrm{p}$ & $\mathrm{r}$ & $\mathrm{p}$ \\
\hline Distal 1 & 0.652 & $0.003^{*}$ & - & - & - & - \\
\hline Distal 2 & - & - & -0.055 & 0.828 & - & - \\
\hline Distal 3 & - & - & - & - & 0.443 & 0.066 \\
\hline
\end{tabular}

for correction of the inclined implants included bar, ball, or locators ${ }^{3,7,9,10}$. However, the clinicians focused on the prosthetic outcome rather than the biologic outcome regarding marginal bone loss around the implant. Moreover, previous studies ${ }^{24,25}$ found no correlation between the radiographic findings and the peri-implant clinical parameters when two implants with Locator attachments were used to retain mandibular overdentures.

The absence of correlations between the radiographic findings and the peri-implant clinical parameters suggests that these parameters are of limited clinical value in assessing and predicting future peri-implant bone loss. Reviewing the literature, there were no relevant clinical studies available to compare the radiographic findings of the present study according to the author's knowledge. 
The study findings revealed a statistically insignificant difference in peri-implant bone loss at the mesial aspect between both groups during the1st year with less peri-implant bone loss with locator group. This reported lack of significance between groups in the present study may be attributed to the better volume and density of the anterior mandible, using at least $6 \mathrm{~mm}$ of residual alveolar bone width which allowed sufficient bone thickness and blood supply for insertion of standard implant diameter of $3.5 \mathrm{~mm}^{26}$, the use of $13 \mathrm{~mm}$ long implants that helped in increasing the implant anchorage in the mandibular anterior bone ${ }^{3}$ and delayed loading protocol ${ }^{27},{ }^{28}$

Although, there was insignificant difference in peri-implant bone loss between the two groups. But, ball group recorded a significant increase in peri-implant bone loss $(0.26)$ in comparison to locator group (0.23). These findings coincide with the finite element study conducted by El-Anwar et $\mathbf{a l},{ }^{27}$ who reported that Locator attachment had decreased amount of stress values at the implantlocator junction in comparison to ball attachment which may be as a result of decreased height and increased diameter of the locator attachment than ball attachment .

While at the $2^{\text {nd }}$ and 3 rd follow-up years, the study recorded a statistically significant differences in bone loss in both groups at the mesial aspect that nearly had the same results and located within the normal range of acceptable criteria for implant success. Ebadian et $\mathbf{a l}^{29}$ reported that ball attachments with reduced collar height and locator attachments with increased restorative space provided favorable biomechanical results and less stresses on the implant.

Withstanding; in this prospective study at the 2ndand, 3rd year follow-up period, there was a statistically significant decrease in bone loss in both groups that may be a result of using angled abutments to adjust implants inclination, to decrease stresses on the implant and to achieve a parallel path of insertion/ removal of the definitive prosthesis. This is concurred with Tian et al. ${ }^{30}$ who examined the tension in tissues surrounding the implant with the use of angled abutments on one-unit dental implants in their FEA study, reported that the use of angled abutments reduced the stresses and showed a better stress distribution at the implant-bone interface. Also, Clelland et al. ${ }^{31}$ demonstrated that strains produced by angled abutments up to $35^{\circ}$ were within the physiological zone with respect to compressive and tensile forces.

The recorded insignificant differences in periimplant bone loss at the distal aspect of both groups during observation periods of the study may be attributed to the possibility of convenient cleansing of highly polished prefabricated abutments that might enhance plaque control.

The significant decrease in the peri-implant bone loss at mesial and distal aspects at the 2nd and 3rd follow-up years in both groups of the study may be due to the gradual decrease of stress on the two implants as a result of the decrease in rotational movement of the overdenture resulted from more overdenture settling with time. This explanation is concurred with UTZ ${ }^{32}$ that the denture settlement which decrease gradually by time and result in decrease in the overdenture rotational movement, decrease stresses on the implants and subsequently less bone loss around implants.

Peri-implant bone loss at the distal aspect was more than that at the mesial aspect around the implants of both groups in the present study. These results were in agreement with previous in vitro studies ${ }^{33,34}$ that reported more distal stresses around the inclined implants. Pigozzo et $\mathbf{a l} .{ }^{33}$ reported that angled implants tended to move in an inclined manner when they received a perpendicular force on the overdenture occlusal plane. Also, Federick and Caputo ${ }^{34}$ found higher stress transmitted to the distal side of $17^{\circ}$ inclined implants from midline. 
The weak positive correlation between periimplant bone loss in the mesial and in the distal aspects and time of measurments recorded in the present study did not coincide with previous study ${ }^{35}$ performed by using tilted implants with bar retained mandibular overdenture. This finding may be attributed to easy plaque control of stud attachment in comparison to difficult plaque control of inaccessible areas when using prefabricated bar.

\section{CONCLUSION}

Even peri-implant bone loss located in the normal range of accepted criteria but it was higher at the distal aspect than that at the mesial aspect for both groups. The locator attachment can be considered more favorable than the ball attachments regarding the marginal bone loss around 30-degree divergent two implants retaining mandibular overdentures.

\section{Conflict of interest}

None

\section{REFERENCES}

1. Anas El-Wegoud M, Fayyad A, Kaddah A, Nabhan A. Bar versus ball attachments for implant-supported overdentures in complete edentulism: A systematic review. J Clin Implant Dent Relat Res. 2017;1-8.

2. Khadivi V. Correcting a nonparallel implant abutment for a mandibular overdenture retained by two implants: A clinical report. J Prosthet Dent 2004; 92:216-9.

3. Akkad S, Richards M. Solutions for Severely Angulated Implants in the Mandibular Overdenture: A Clinical Report. J Prosthodont. 2009; 18:342-7.

4. Shor A, Shor K, Goto Y .Implant-Retained Overdenture Design for the Malpositioned Mandibular Implants. Clinical Report. Compendium, 2006; 27: 7; 353.

5. Kobayashi M, Srinivasan M, Ammann P, Perriard J, Ohkubo C, Müller F, Belser UC, Schimmel M. Effects of in vitro cyclic dislodging on retentive force and removal torque of three overdenture attachment systems. Clin Oral Implants Res. 2014; 25:426-434.

6. Srinivasan M, Kalberer N, Maniewicz S, Müller F. Implant overdentures retained by self-aligning stud-type attachments: A clinical report. J Prosthet Dent. 2020; 123:6-14.
7. Loney RW, Lee CJ, Michaud PL, Cook TJA. Use of a dental surveyor to ensure optimal seating of implant overdenture attachments. J Prosthet Dent. 2019; 121:381-3.

8. Ravidà A, Barootchi S, Tattan M, Saleh MHA, GargalloAlbiol J, Wang HL. Clinical outcomes and cost effectiveness of computer-guided versus conventional implantretained hybrid prostheses: A long-term retrospective analysis of treatment protocols. J Periodontol. 2018; 89: 1015-24.

9. Yang TC, Maeda Y, Gonda T, Kotecha S. Attachment systems for implant overdenture: influence of implant inclination on retentive and lateral forces. Clin Oral Implants Res. 2011; 22:1315-9.

10. Bidra AS, Agar JR. Management of misangulated implants for a maxillary overdenture with spherical abutments: a clinical report. J Prosthet Dent. 2011; 106:209-13.

11. Walton JN, Huizinga SC, Peck CC. Implant angulation: a measurement technique, implant overdenture maintenance, and the influence of surgical experience. Int J Prosthodont. 2001;14:523-30.

12. ELsyad MA, Emera RM, Ashmawy TM. Effect of Distal Implant Inclination on Dislodging Forces of Different Locator Attachments Used for Mandibular Overdentures: An In Vitro Study. J Prosthodont. 2019; 28: e666-e674.

13. Laleman I, Bernard L, Vercruyssen M, Jacobs R, Bornstein MM, Quirynen M. Guided Implant Surgery in the Edentulous Maxilla: A Systematic Review. Int J Oral Maxillofac Implants. 2016; 31 :s103-17.

14. Uludag B, Celik G, Goktug G. Prosthetic solution for unfavorably inclined maxillary implants: a case report. J Oral Implantol. 2008; 34:111-4.

15. Leite ARP, Marin DOM, Giro G, Pero AC, Pinelli LAP, Reis JMDSN. Custom Cast Ball Attachments Used on Outdated Implants to Restore a Maxillary Implant-Supported Overdenture. J Oral Implantol. 2017; 43:297-301.

16. Mumcu E, Dereci Ö. Assessment of the Effect of Clinical Independent Risk Factors on Marginal Bone Loss in 2-Implant-Supported Locator-Retained Mandibular Overdentures. J Oral Implantol. 2019; 45:207-212.

17. Ramaglia L, Toti P, Sbordone C, Guidetti F, Martuscelli $\mathrm{R}$, Sbordone L. Implant angulation: 2-year retrospective analysis on the influence of dental implant angle insertion on marginal bone resorption in maxillary and mandibular osseous onlay grafts. Clin Oral Investig. 2015; 19:769-79. 
18. Hegazy S, Elmekawy N, Emera RM. Peri-implant Outcomes with Laser vs Nanosurface Treatment of Early Loaded Implant-Retaining Mandibular Overdentures. Int J Oral Maxillofac Implants. 2016;31:424-30

19. Čelebić A, Peršić S, Kovačić I, Buković D, Lešić N, Rener-Sitar K. Comparison of Three Prosthodontic Treatment Modalities for Patients with Periodontally Compromised Anterior Mandibular Teeth: A 2-year follow-up study. Acta Stomatol Croat. 2019; 53:4-16.

20. Traini T, Berardini M, Congedi F, Sinjari B, Trisi P, Caputi S. Impact of Second Stage Surgery on Bone Remodeling Around New Hybrid Titanium Implants: A Prospective Clinical Study in Humans. Implant Dent. 2017; 26:121-8.

21. Abdel-Khalek EA. Fabrication of a Simple Acrylic Template to Standardize Periapical Radiographs for Implants Retaining Mandibular Bar Overdentures. J Prosthodont. 2019;28:e657-e660

22. Romero-Ruiz MM, Mosquera-Perez R, Gutierrez-Perez JL, Torres-Lagares D. Flapless implant surgery: A review of the literature and 3 case reports. J Clin Exp Dent. 2015; 7:e146-e152.

23. Kim YT, Lim GH, Lee JH, Jeong SN. Marginal bone level changes in association with different vertical implant positions: a 3-year retrospective study. J Periodontal Implant Sci. 2017; 47:231-239.

24. El-Sheikh AM, Shihabuddin OF, Ghoraba SM. Two versus three narrow-diameter implants with locator attachments supporting mandibular overdentures: a two-year prospective study. Int J Dent. 2012; 2012:285684.

25. Elsyad MA, Elsaih EA, Khairallah AS. Marginal bone resorption around immediate and delayed loaded implants supporting a locator-retained mandibular overdenture. A 1-year randomised controlled trial. J Oral Rehabil. 2014; 41:608-18
26. Klein MO, Schiegnitz E, Al-Nawas B. Systematic review on success of narrow-diameter dental implants. Int J Oral Maxillofac Implants. 2014; 29:43-54.

27. El-Anwar MI, Yousief SA, Soliman TA, Saleh MM, Omar WS. A finite element study on stress distribution of two different attachment designs under implant supported overdenture. Saudi Dent J. 2015; 27:201-7.

28. Meijer HJ, Raghoebar GM, Batenburg RH, Visser A, Vissink A. Mandibular overdentures supported by two or four endosseous implants: a 10-year clinical trial. Clin Oral Implants Res. 2009; 20:722-8.

29. Ebadian B, Farzin M, Talebi S, Khodaeian N. Evaluation of stress distribution of implant-retained mandibular overdenture with different vertical restorative spaces: A finite element analysis. Dent Res J (Isfahan). 2012; 9:741-7.

30. Tian K, Chen J, Han L, Yang J, Huang W, Wu D. Angled abutments result in increased or decreased stress on surrounding bone of single-unit dental implants: a finite element analysis. Med Eng Phys. 2012; 34:1526-31.

31. Clelland NL, Gilat A. The effect of abutment angulation on stress transfer for an implant. J Prosthodont. 1992; 1:24-8.

32. Utz KH. Studies of changes in occlusion after the insertion of complete dentures (part II). J Oral Rehabil. 1997; 24:376-84.

33. Pigozzo MN, Laganá DC, Sesma N, Souza GF, Ichi AL. Photoelastic stress analysis in mandibular bone surrounding bar-clip overdenture implants. Braz Oral Res. 2014; 28:S1806-83242013005000034

34. Federick DR, Caputo AA. Effects of overdenture retention designs and implant orientations on load transfer characteristics. J Prosthet Dent. 1996; 76:624-32.

35. Abdel-Khalek EA, Khalifa AK, Elmekawy N. The effect of using prefabricated bars on marginal bone loss around tilted or axially placed and immediately loaded implants for retaining mandibular overdentures. J Dent Implant 2018; 8:54-60 